\section{Commentary: Prosthesis-patient mismatch. A blast from the past?}

\author{
Marco Moscarelli, MD, ${ }^{\mathrm{a}}$ and Mario Gaudino, $\mathrm{MD}^{\mathrm{b}}$
}

As surgeons, we do know how important is to avoid the implantation of "small" aortic valve prosthesis. We are also aware that a narrow aortic root may be pose technical challenges and sometimes require aortic annulus-enlargement procedures.

The concept of prosthesis-patient mismatch (PPM) was introduced by Rahimtoola ${ }^{1}$ back in 1978: "Mismatch can be considered to be present when the effective prosthetic valve area, after insertion into the patient, is less than that of a normal human valve." This notion was eventually revised by Pibarot and Dumesnil. ${ }^{2}$ They proposed avoiding an indexed orifice area (EOAi) less than $0.85 \mathrm{~cm}^{2} / \mathrm{m}^{2}$ to prevent PPM. This was based on the steep increase in the mean gradient if EOAi falls below this cut-off.

In this issue of the Journal, Vriesendorp and colleagues ${ }^{3}$ challenge this concept. They polled data from 2171 patients who underwent aortic valve replacement with surgical bioprosthesis in 5 trials and evaluated the transthoracic echocardiographic images at 1-year follow-up assessing the association between EOAi and mean gradient using the same model applied by Pibarot and Dumesnil.

Of note, Vriesendorp and associates also found that the relation between EOAi and mean transvalvular aortic gradient did not differ between patients with and without obesity; this may support the use of lower cut-off values of EOAi for the population with obesity.

Why this study is important? The concept of PPM so far has been based on the assumption of the exponential relation between EOAi and mean aortic gradient (with a steep increase in the mean gradient when EOAi goes below

From the ${ }^{\mathrm{a}}$ Department of Cardiovascular Surgery, GVM Care \& Research, Bari, Italy; and ${ }^{\mathrm{b}}$ Department of Cardio-Thoracic Surgery Weill Cornell Medicine, New York, NY.

Disclosures: The authors reported no conflicts of interest.

The Journal policy requires editors and reviewers to disclose conflicts of interest and to decline handling or reviewing manuscripts for which they may have a conflict of interest. The editors and reviewers of this article have no conflicts of interest

Received for publication Oct 27, 2020; revisions received Oct 27, 2020; accepted for publication Oct 27, 2020; available ahead of print Nov 7, 2020.

Address for reprints: Mario Gaudino, MD, Department of Cardiothoracic Surgery, Weill Cornell Medicine, 525 East 68th St, New York, NY 10065 (E-mail: mfg9004@med.cornell.edu).

J Thorac Cardiovasc Surg 2022;164:830-1

$0022-5223 / \$ 36.00$

Copyright (c) 2020 by The American Association for Thoracic Surgery

https://doi.org/10.1016/j.jtcvs.2020.10.117

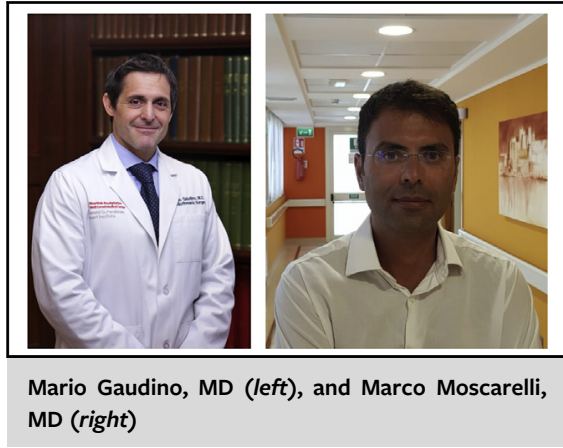

CENTRAL MESSAGE

A linear rather than exponential relation between EOAi and mean gradient may undermine the original categorical definition of PPM. The concept of PPM also should be revised in patients with obesity.

$0.85 \mathrm{~cm}^{2} / \mathrm{m}^{2}$ ). Vriesendorp and colleagues found a less-pronounced exponential relationship between EOAi and mean aortic gradient than previously demonstrated by Pibarot and Dumesnil, and this suggests that the current definition of PPM may be overconservative in some case.

This concept is the foundation of the "EOAi charts" that we consult before starting a case to select the appropriate valve size to predict and prevent PPM. This study has some limitations. Perhaps the main limitation is that only echocardiographic measurements were used to analyze the relation between EOAi and mean aortic gradient.

Why this study may be less relevant than what we may expect? Transcatheter aortic valve replacement (TAVR) is becoming the treatment of choice for the majority of patients with symptomatic aortic valve stenosis; some studies are also supporting superiority of TAVR against surgery extending the adoption in low-risk context. ${ }^{4}$

While concerns still exist with regard to TAVR durability and the incidence of postoperative pacemaker, the hemodynamic profile of the new percutaneous valves is outstanding, with trivial transprosthesis mean gradient generally lower than standard surgical valve. ${ }^{5,6}$ This evidence may be set in relation to differences in TAVR design, such as the absence of a sewing ring and the supra-annular profile.

TAVR may be particularly indicated in the patients with obesity to avoid any risk for PPM. With this in mind, indepth speculation and complex mathematical modeling to 
predict PPM after surgical aortic valve replacement may be hampered by the shift of practice toward catheter-based technologies.

\section{References}

1. Rahimtoola SH. The problem of valve prosthesis-patient mismatch. Circulation. 1978:58:20-4.

2. Pibarot P, Dumesnil JG. Hemodynamic and clinical impact of prosthesis-patient mismatch in the aortic valve position and its prevention. J Am Coll Cardiol. 2000;36:113-4.
3. Vriesendorp M, Deep M, Reardon M, Kiaii B, Bapat V, Labrousse L, et al. Why the categorization of indexed effective orifice area is not justified for the classification of prosthesis-patient mismatch. J Thorac Cardiovasc Surg. 2022;164:822-9.e6.

4. Popma JJ, Deeb GM, Yakubov SJ, Mumtaz M, Gada H, O’Hair D, et al; Evolut Low Risk Trial Investigators. Transcatheter aortic-valve replacement with a self-expanding valve in low-risk patients. $N$ Engl J Med. 2019;380:1706-15.

5. Takagi H, Umemoto T, ALICE (All-Literature Investigation of Cardiovascular Evidence) Group. Prosthesis-patient mismatch after transcatheter aortic valve implantation. Ann Thorac Surg. 2016;101:872-80.

6. Clavel MA, Webb JG, Pibarot P, Altwegg L, Dumont E, Thompson C, et al. Comparison of the hemodynamic performance of percutaneous and surgical bioprostheses for the treatment of severe aortic stenosis. J Am Coll Cardiol. 2009; 53:1883-91.
See Article page $\mathbf{8 2 2}$.

\section{Commentary: The problem of valve prosthesis-patient mismatch revisited}

Derrick Y. Tam, MD, PhD, ${ }^{\mathrm{a}}$ and Joanna Chikwe, $\mathrm{MD}^{\mathrm{b}}$

In 1978, Shahbudin Rahimtoola published a review article in Circulation titled "The Problem of Valve ProsthesisPatient Mismatch," described as "when the effective prosthetic valve area, after insertion into the patient, is less than that of a normal human valve." ${ }^{1} \mathrm{He}$ observed that although this was usually mild to moderate and often of no immediate clinical significance, it was occasionally a severe problem that left the patient hemodynamically and symptomatically worse after valve replacement. In this landmark review, Dr Rahimtoola articulated 3 themes that

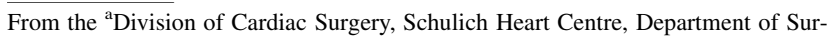
gery, Sunnybrook Health Sciences Centre, University of Toronto, Toronto, Ontario, Canada; and ${ }^{\mathrm{b}}$ Smidt Heart Institute, Cedars-Sinai Medical Center, Los Angeles, Calif.

Disclosures: The authors reported no conflicts of interest. Cedars-Sinai Medical Center receives fees from Edwards Lifesciences and Medtronic for speaker, consulting, and research activities.

The Journal policy requires editors and reviewers to disclose conflicts of interest and to decline handling or reviewing manuscripts for which they may have a conflict of interest. The editors and reviewers of this article have no conflicts of interest.

Received for publication Nov 25, 2020; revisions received Nov 25, 2020; accepted for publication Nov 30, 2020; available ahead of print Dec 5, 2020.

Address for reprints: Derrick Y. Tam, MD, PhD, Division of Cardiac Surgery, Schulich Heart Centre, Department of Surgery, Sunnybrook Health Sciences Centre, University of Toronto, 2075 Bayview Ave, H408, Toronto, Ontario, Canada M4N3M5 (E-mail: derrick.tam@utoronto.ca).

J Thorac Cardiovasc Surg 2022;164:831-2

$0022-5223 / \$ 36.00$

Copyright (c) 2020 by The American Association for Thoracic Surgery

https://doi.org/10.1016/j.jtcvs.2020.11.145

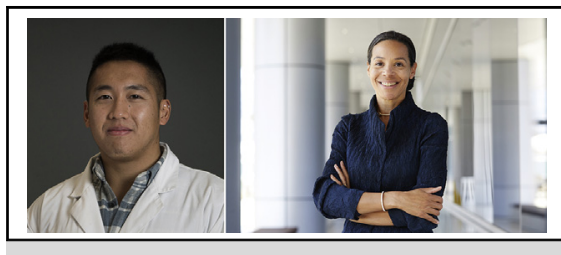

Derrick Y. Tam, MD, PhD, and Joanna Chikwe, MD

CENTRAL MESSAGE

The indexed effective orifice area may not accurately predict elevated prosthetic valve gradients.

have become dogma: (1) correcting effective valve area for body size; (2) assessing valve prostheses during exercise, not just at rest; and (3) what he depicted as an almost exponential relationship between valve area and transvalvular gradient. Similar to coronary obstruction, this implied that relatively large reductions in surface area result in minimal incremental obstruction until the effective orifice is reduced to $<35 \%$ of normal, when small incremental reductions result in precipitous rises in gradient.

Almost 2 decades later, based on a series of 61 patients, Pibarot and colleagues ${ }^{2,3}$ quantified the prosthesis-patient mismatch, indexing prosthetic valve effective orifice area (iEOA) to patient body surface area, defining mismatch as $\mathrm{iEOA} \leq 0.85 \mathrm{~cm}^{2} / \mathrm{m}^{2}$ and later defining severe mismatch 